\title{
Solitary Peutz-Jeghers Type Hamartomatous Polyp Arising from the Appendix
}

\author{
Mariana Sant'Anna ${ }^{a}$ Elisa Gravito-Soares ${ }^{a, b} \quad$ Marta Gravito-Soares ${ }^{a}$ b \\ Sofia Mendes ${ }^{a}$ Pedro Narra Figueiredo ${ }^{a}$, b \\ aGastroenterology Department, Centro Hospitalar e Universitário de Coimbra, Coimbra, Portugal; baculty of \\ Medicine, University of Coimbra, Coimbra, Portugal
}

\section{Keywords}

Appendix · Hamartoma · Endoscopy

\section{Pólipo hamartomatoso solitário do tipo Peutz- Jeghers com crescimento intra-apendiceal}

\section{Palavras Chrave}

Apêndice, Pólipo Hamartomatoso, Endoscopia

Digestive hamartomatous polyps may be solitary or multiple, the latter often associated with genetic predisposition $[1,2]$. Solitary Peutz-Jeghers (PJ)-type hamartomatous polyps represent a rare and distinct entity from the classic PJ syndrome, an autosomal dominant genetic disorder characterized by the development of multiple polyps in the gastrointestinal (GI) tract in association with patches of hyperpigmentation in the mouth, hands and feet $[1,3]$. It is important to distinguish these two entities since the latter is associated with a lifetime cumulative risk of up to $93 \%$ for development of malignancies (such as colorectal, breast, small bowel, gastric and pancreatic cancers), but the first seems benign in its course. Solitary PJ polyps are diagnosed in patients with an iso-

Karger@karger.com www.karger.com/pjg

Karger!"
C 2022 Sociedade Portuguesa de Gastrenterologia. Published by S. Karger AG, Basel

This is an Open Access article licensed under the Creative Common Attribution-NonCommercial-4.0 International License (CC BY-NC) (http://www.karger.com/Services/OpenAccessLicense), applicable to the online version of the article only. Usage and distribution for commercial purposes requires written permission. lated hamartomatous polyp of the GI tract, no familiar history of polyposis and no typical phenotype [3].

An 80-year-old man with a history of sigmoidectomy due to an obstructive T2N0M0 colorectal cancer underwent a surveillance thoracoabdominopelvic CT scan showing a voluminous endoluminal polyp at the caecum (Fig. 1). He was referred to our reference centre for colonoscopy. A 4-cm diameter pedunculated and congestive polyp was identified with a short and thick stalk arising from the appendiceal orifice. We proceeded to its en bloc resection using a $25-\mathrm{mm}$ oval diathermic snare after stalk injection with diluted adrenaline 1:10,000, normal saline and methylene blue with polyp recovery for histology (Fig. 2a-c, 3a). The polyp was confirmed to be a hamartomatous polyp of the PJ type (R0 resection) with arborizing pattern of vascularized smooth-muscle tissue axes covered by elongated veliform crypts and occasional intraluminal necrosis with no dysplasia (Fig. 3b). The patient had no typical manifestations of PJ syndrome or family history. His follow-up showed no complications related to the procedure, including bleeding or acute appendicitis (prophylactic antibiotic was not used).

Solitary PJ-type hamartomatous polyps of the GI tract are rare, and appendiceal location is even rarer. Accord- 


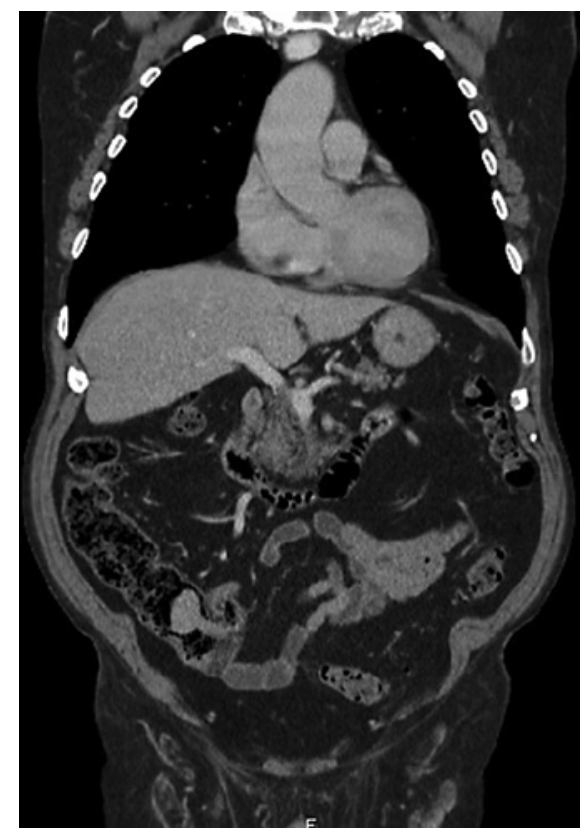

Fig. 1. Thoracoabdominopelvic CT scan (coronal section) with intravenous contrast showing a voluminous endoluminal polyp at the caecum measuring $40 \times 31 \mathrm{~mm}$ with homogeneous enhancing. No alterations at surgical anastomosis level.
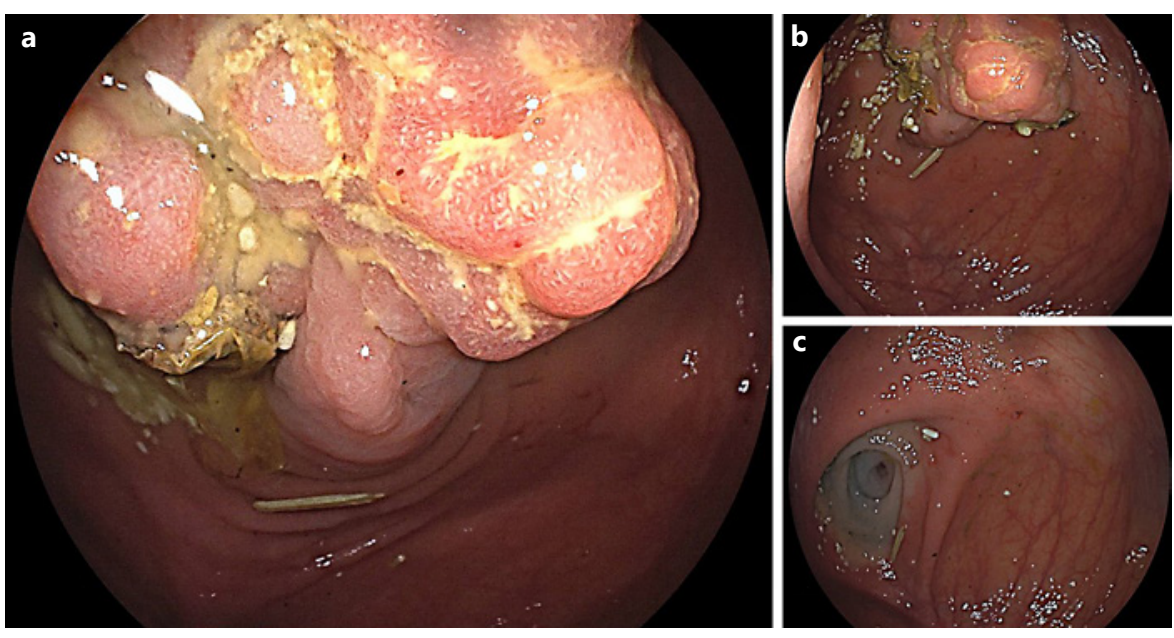

Fig. 2. a, b Colonoscopy performed showing a 4-cm diameter pedunculated and congestive polyp with a short and thick stalk arising from the appendiceal orifice. c En bloc endoscopic resection was performed using a diathermic snare after stalk injection with diluted adrenaline 1:10,000, normal saline and methylene blue with no complications.
Fig. 3. a Macroscopic specimen of endoscopic resection. b Histopathological analysis revealed a hamartomatous polyp of Peutz-Jeghers-type with arborizing pattern of vascularized smooth-muscle tissue axes covered by elongated crypts with veliform pattern and occasional intraluminal necrosis with no dysplasia (R0 resection).
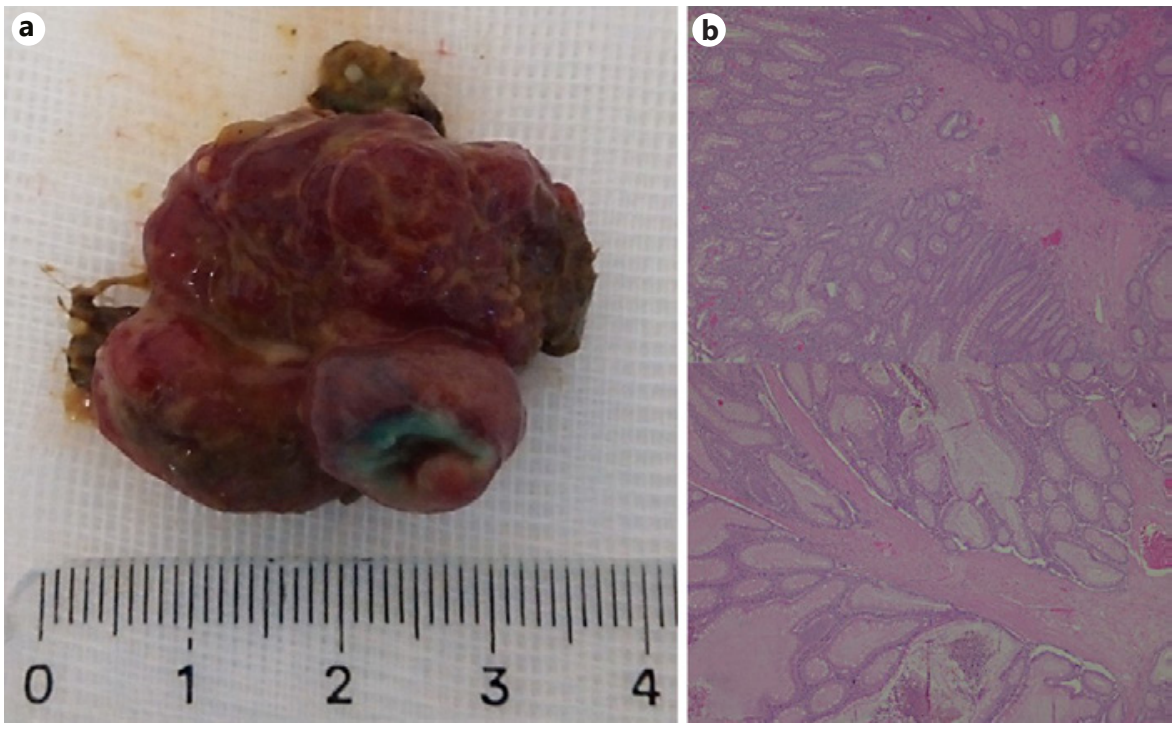

ing to the largest case study to date on the follow-up of solitary PJ polyps, they are normally large in size $(>15$ $\mathrm{mm}$ ), mostly pedunculated and localized primarily in the colon (even though they have been described in all of the GI tract, except in the oesophagus) [3]. During a mean endoscopic follow-up of 4.5 years (range: $0.1-16.1$ years) after excision, no recurrence was observed, making endoscopic follow-up after diagnosis of a PJ polyp unnecessary [3]. Although malignant transformation seems rare, extensive genetic and epigenetic changes have been de- 
scribed in this type of polyps that may contribute to cancer risk [4]. Adding to the risk of other complications related to intraluminal polyp growth (colonic obstruction, intussusception, appendicitis or GI bleeding), and since endoscopic resection allows for a histological diagnosis, polypectomy is always advisable $[2,5]$. This case highlights the importance of recognizing the existence of solitary $\mathrm{PJ}$ polyps as a distinct entity from PJ syndrome, with drastic consequences of misdiagnosis in terms of followup and prognosis. Additionally, the appendiceal location of these polyps is rare and represents a very technically challenging location for endoscopic therapy.

\section{Acknowledgement}

The authors would like to thank Dr. Maria Augusta Cipriano and Dr. João Fraga for their kindness in providing histopathological images.

\section{Statement of Ethics}

The subject of this clinical case has given us an oral consent to publish his case, including the publication of images. All information about the identity of the subject has been removed.

\section{Conflict of Interest Statement}

The authors have no conflicts of interest to declare.

\section{Author Contributions}

The first 4 authors participated in the endoscopic resection and have written/revised the paper. Pedro Narra Figueiredo is the head director of the Gastrenterology Department in which this case was reported and also revised the paper.

\section{References}

1 Cauchin E, Touchefeu Y, Matysiak-Budnik T. Hamartomatous tumors in the gastrointestinal tract. Gastrointest Tumors. 2015;2(2):6574.

2 Calva D, Howe JR. Hamartomatous polyposis syndromes. Surg Clin North Am. 2008;88(4): 779.

3 Iwamuro M, Aoyama Y, Suzuki S, Kobayashi S, Toyokawa T, Moritou Y, et al. Long-term outcome in patients with a solitary PeutzJeghers polyp. Gastroenterol Res Pract. 2019; 2019:1-5.
4 Linhart H, Bormann F, Hutter B, Brors B, Lyko F. Genetic and epigenetic profiling of a solitary Peutz-Jeghers colon polyp. Mol Case Stud. 2017;3(3):a001610.

5 Choi CI, Kim DH, Jeon TY, Kim DH, Shin NR, Park DY. Solitary Peutz-Jeghers-type appendiceal hamartomatous polyp growing into the terminal ileum. World J Gastroenterol. 2014;20(16):4822. 